http://dx.doi.org/10.30681/23588403v13i0204

\title{
ENTRE REPRESENTAÇÕES E AFETOS EM VOCÊ TEM A VIDA INTEIRA
}

Data de recebimento: 18/09/2019

Aceite: 12/11/2019

\author{
Joémerson de Oliveira SALES (SEDUC/MT) ${ }^{1}$ \\ João Victor BARBOSA (SEDUC/MT) ${ }^{2}$ \\ Rosana Arruda de SOUZA (UFMT) ${ }^{3}$
}

\begin{abstract}
Resumo: Nossa proposta de trabalho é discutir as relações afetivas por meio das perspectivas dos três protagonistas de Você tem a vida inteira, de Lucas Rocha. O romance aborda como foco principal as relações entre sorodiscordantes homossexuais, apresentando o duplo preconceito enfrentado por essas pessoas. Dessa forma, nossa reflexão assenta-se no olhar do mundo moderno e suas implicações no desenrolar da própria vida.
\end{abstract}

Palavras-chave: Relações Afetivas. Sorodiscordantes. Mundo Moderno.

Abstract: Our work proposal is to discuss the affective relationships through the perspectives of the three protagonists of You have a lifetime, by Lucas Rocha. The novel focuses mainly on the relationships between homosexual serodiscordants, presenting the double prejudice faced by these people. Thus, our reflection is based on the look of the modern world and its implications on the unfolding of life itself.

Keywords: Affective Relations. Serodiscordant. Modern world.

Introdução

Quando falamos de relações afetivas, mas especificamente de relações amorosas, o cenário atual nos entrega o amor sob uma nova roupagem: o amor que finge não ser tal como ele é; um amor fugidio, quase escasso, que deixou há muito de ser assegurado pela

interprojeção de corpos e pela mediação de conversas em busca do aconchego e da plenitude. Os corpos, hoje, intermedeiam-se por imagens (as várias máscaras utilizadas nas redes

\footnotetext{
${ }^{1}$ Licenciado em Letras com habilitação em Língua Portuguesa e suas respectivas literaturas pela UFMT/CUR e mestre em Estudos de Linguagem com ênfase em Estudos Literários pela Universidade Federal de Mato Grosso (UFMT), professor de Língua Portuguesa na escola Plena Pindorama de Rondonópolis - SEDUC-MT.

${ }^{2}$ Estudante no segundo ano do ensino médio na escola Plena Pindorama.

${ }^{3}$ Licenciada em Letras com habilitação em Língua Portuguesa e suas respectivas Literaturas pela UFMT/CUR e mestre em Estudos de Linguagem com ênfase em Estudos Literários pela Universidade Federal de Mato Grosso (UFMT). Em doutoramento em Estudos de Linguagem pela Universidade Federal de Mato Grosso (UFMT). Bolsista Capes/Fapemat.
} 
sociais); e a busca, a esta cabe uma indagação bastante plausível quando o assunto demarca as relações amorosas: o que se busca? Em meio a conversas rápidas, ao boom de encontros virtuais com desconhecidos, ao boom de encontros, sim, de carne e osso, mas com sujeitos que permanecem desconhecidos um ao outro, pergunta-se: o que se busca? O que se busca no outro, quando o outro passou a ser tão outro, tão distante?

Num caminho que atravessa toda esta discussão e, ao mesmo tempo, vai de encontro a ela, temos o romance Você tem a vida inteira, de Lucas Rocha. Três jovens protagonizam a história: Ian, Victor e Henrique. Victor inicia um relacionamento com Henrique, mas fica abalado depois de saber que este é soropositivo, e conhece Ian no mesmo dia em que ambos foram fazer o teste de HIV. A partir deste dia, a história dos três irão se entrecruzar, passando por experiências que vão desde o lidar com o preconceito seja pela doença seja pela homossexualidade, até o reconhecimento da constitucionalidade das relações de amizade e de amor.

Tudo isso em meio a conversas no whatsapp e no facebook; a jovens universitários e jovens se preparando para o Enem; demonstrando que o tempo retratado na história é bastante atual e se conjuga no escopo da modernidade, a qual, conforme Zygmunt Bauman, apresenta o paradigma do fluxo contínuo das coisas, em que não se constroem raízes, e mesmo o amor entraria como um bem de consumo bem pouco durável. Porém, os laços criados entre Ian, Victor e Henrique demonstrarão o contrário. Ainda que eles vivam em meio à correria da cidade grande e a despeito de suas vivências serem atravessadas pela transitoriedade das relações midiáticas, o tempo entre eles perdura. Eles têm tempo de olhar para o outro, têm tempo de compartilhar as experiências, têm tempo de trabalhar, de estudar, de consolar o próximo, de defender os amigos, têm tempo para amar.

Por fim, o romance nos entrega uma história de três perspectivas. Os três protagonistas aparecem como narradores, intercalando-se a cada capítulo, e cada capítulo leva o título com o nome daquele que vai narrar no momento. Assim, vemos como cada um enxerga, por exemplo, o lidar (direta ou indiretamente) com o HIV e como cada um aprende, ao seu modo, a não deixar que a doença seja maior que a vontade deles de viver. Diante disso, nosso objetivo, neste trabalho, consiste em analisar como as relações de afeto se conjugam na história estando elas assentadas sob as condições do que chamamos mundo moderno. Para tanto, dialogaremos com Bauman, a respeito da modernidade líquida e do amor líquido, e com autores que complementam o olhar do estudioso. 


\section{Do estranhamento aos laços de amizade e amor}

Apesar de a narrativa de Você tem a vida inteira centrar-se tematicamente a respeito do vírus do HIV/AIDS, as perspectivas das três personagens principais nos mobilizam a refletir intensamente sobre a vida, o amor e as relações de amizade. $\mathrm{O}$ romance ${ }^{4}$ é a primeira obra de Lucas Rocha, autor brasileiro.

A narrativa inicia com Ian Gonçalves que, ao realizar o teste rápido, tem como resultado a sua sorologia positiva. A personagem mesmo sendo informada dos avanços em relação ao tratamento sente-se sozinha. Vejamos:

- Olha, as pessoas não morrem mais disso. Se você fizer o tratamento corretamente, pode ter uma vida tão normal quanto a de qualquer outra pessoa. Mas vou deixar que a infectologista converse sobre isso com você.

Você, ela diz.

No singular.

Estou completamente sozinho

$[\ldots]$

- A gente tem que viver, não é? - Sorrio, repetindo em voz alta o coletivo, para reafirmar a mim mesmo que não estou sozinho. E repetindo mentalmente que não devo começar a chorar na frente dela. - Espero que dê tudo certo.

- Vai dar. - Ela me encoraja, sorrindo pela primeira vez desde que colocou aqueles olhos azuis em mim. - Se precisar de algum apoio, você pode procurar nosso setor de psicologia ou assistência social. Aqui no centro de tratamento você terá tudo o que precisar, e uma das grandes vantagens é que no Brasil o SUS cobre todo o tratamento sem maiores complicações, tudo gratuito. Você está em boas mãos.

Você, você, você.

Ela não deixa de enfatizar o singular.

Estou completamente sozinho

(ROCHA, 2018, p. 12 - grifo do autor).

A sensação de estar sozinho, se pensarmos nas relações da pós-modernidade em Bauman, sentida por Ian é afiançada pela

incapacidade de enfrentar a pluralidade de seres humanos e a ambivalência de todas as decisões classificatórias, ao contrário, se autoperpetuam e reforçam: quanto mais eficazes a tendência à homogeneidade e o esforço para eliminar a diferença, tanto mais difícil sentir-se à vontade em presença de estranhos, tanto mais ameaçadora a diferença e tanto mais intensa a ansiedade que ela gera (BAUMAN, 2001, p. 123).

\footnotetext{
${ }^{4}$ Vale destacar que o romance faz parte do Kit Gay, que é constituído por mais dois romances, a saber: George, de Alex Gino (2016) e Dois garotos se beijando, David Levithan (2015).
} 
A dificuldade em se sentir acolhido num coletivo marcado pela expressão "a gente" é a contrafeita direcionada ao uso do pronome pessoal "você", que se enfatiza e traz à tona a tendência da homogeneidade que nesse caso se ilustra por um espaço marcado por um nicho especifico, a saber, o grupo homossexual. Ian sente-se sozinho, pois não está na mesma posição da psicóloga que, apesar de sua boa intenção de não deixar o rapaz mais desolado, reforça sua diferença e ao mesmo tempo o desloca para uma ação, a de realizar o tratamento.

Em outra cena, quando Ian se depara com Victor Mendonça, a sensação de estranheza também se marca abrindo margem para outra direção. Observemos:

- Parabéns. - Sou pego de surpresa pela voz ao meu lado. Estou tão aliviado com as boas notícias que nem tinha percebido o garoto sentado no ponto de ônibus, o mesmo que saiu da sala da psicóloga antes que eu entrasse.

$[\ldots]$

Ele ainda olha para baixo, sem conseguir levantar a cabeça. Quero dizer que ele deve levantá-la e encarar o mundo de frente, mas não sei qual seria a minha reação caso as notícias não tivessem sido boas para mim.

$[\ldots]$

Ele comprime as palmas das mãos contra o rosto e deixa o papel com seu diagnóstico escapar. Eu me levanto e alcanço a folha antes que o vento a leve embora. Suas costas sobem e descem enquanto ele soluça, completamente sem controle, e tudo que quero é dar um abraço naquele desconhecido e dizer para ele que sim, vai ser difícil, mas que as coisas podem dar certo (ROCHA. 2018, p. 19-21).

O primeiro contato de Victor com Ian se dá por meio de uma ruptura de sensação. Enquanto um está feliz por não ser portador do vírus do HIV, outro está abalado, sem saber o que será da vida agora com o resultado positivo de sua sorologia. Nesta cena, Victor demonstra um comportamento diferente. A personagem age de uma forma mais humana e não reforça o lugar de estranhamento em que se encontra Ian.

O mesmo tratamento de início não é destinado a Henrique. A relação entre Victor e Henrique reforça "à nossa tendência contemporânea obsessiva com poluição e purificação, à nossa tendência de identificar o perigo para a segurança corporal com a invasão de corpos estranhos" (BAUMAN, 2001, p. 126 - grifos nossos). Isso se marca no pensamento da personagem quando é incentivada a continuar a relação com o rapaz: "ele tem uma doença que pode me matar, penso em dizer" (ROCHA, 2018, p. 18 - grifo do autor) e no momento em que está conversando com a psicóloga para saber de seu resultado: "ele poderia ter me infectado!" (ROCHA, 2018, p. 17). 
Victor é uma personagem basilar para entendermos a obra. Em sua estrutura o romance começa pela narrativa de Ian e logo em seguida vem a história de Victor e depois a de Henrique. Essa ordem cria no enredo um efeito potente, uma vez que temos a percepção do recém-infectado, do não infectado e do que já infectado. Victor corresponde ao elo no enredo. Sua atitude é mais complacente com Ian, pois estava numa mesma posição que a dele e diferente da de Henrique.

Bauman fala sobre a não continuidade das relações entre estranhos e diz que esse encontro "é um evento sem futuro [...] uma oportunidade única a ser consumida enquanto dure e no ato, sem adiamento e sem deixar questões inacabadas para outra ocasião" (BAUMAN, 2001, p. 111 - grifos do autor). No entanto, o encontro de Ian e Victor nos apresenta uma quebra neste traço:

Continuo com os atos impulsivos, e não sei bem o que me faz pegar uma caneta do bolso da minha calça e o papel com o diagnóstico dele, mas quando percebo já estou rabiscando meu número de telefone e meu nome de um jeito nervoso e trêmulo no lado de trás da folha. Estendo o papel. - Se precisar conversar com alguém, pode me mandar uma mensagem. Tenho um amigo soropositivo, e posso colocar vocês dois em contato. - Henrique aparece na minha mente e, por mais que eu não queria vê-lo nem pintado de ouro, acho que não se oporia a conversar com alguém que irá passar pelas mesmas dificuldades que ele deve ter enfrentado quando descobriu seu diagnóstico (ROCHA, 2018, p. 22).

A história reverbera, em seu próprio modo de nascer e de ser construída, a solidariedade entre as vozes, driblando a autoridade de um único eu. Não estamos tratando de uma história contada sob várias versões, trata-se de uma história conduzida por mais de uma voz, de forma que possamos ter contato com a experiência com que cada um vivencia direta ou indiretamente a doença.

Com o advento da morte de deus apregoada por Nietzsche, no século XIX, observamos o rebaixamento de tudo aquilo a que se podia transferir uma autoridade criadora, ou, em outras palavras, de tudo aquilo que promulgava um único ponto de vista para as coisas. Nestes termos, anula-se também qualquer caráter transferencial de experiência, visto que cada um tem a sua, cabendo a cada um também o direito de externá-la - pois é única, portanto, não

se pode viver a experiência do outro. O pensamento nietzschiano acabou, de certo maneira, a abrir caminho para formulação das teorias contemporâneas que trazem propostas contra- 
hegemônicas de maneira a oferecer espaço à escuta do outro, rompendo-se, assim, o axioma do ente criador que tinha o poder de falar por ele, como se o mesmo carecesse de voz.

Tratar da mobilização das experiências de vida ganha tamanha relevância principalmente quando observamos, na contramão das exposições e autoexposições nas redes sociais, o recolhimento cada vez mais massivo do eu, que muitas vezes, não deixa de ser o sujeito solitário e carente de diálogo, acuado atrás da tela do celular ou do computador. Assim, os laços promulgados por essas mesmas redes em nada parecem corresponder aos laços na vida real, onde se reluta ao compartilhamento de experiências, reluta-se a todo custo a olhar para o próximo, exceto quando este aparece estampado nas telas. Fora desta, o que temos são pessoas que agem, na comparação feita por Bauman (2001, p. 111), “como a aranha cujo mundo inteiro está enfeixado na teia que ela tece a partir de seu próprio abdômen, o único apoio com que estranhos que se encontram podem contar deverá ser tecido do fio fino e solto de sua aparência, palavras e gestos".

No encontro entre os três rapazes, esses elementos - a aparência, as palavras e os gestos - sempre serão as margens que nortearão o olhar entre eles. Os narradores são pessoas observadoras.

Voltando à cena do teste de HIV, o movimento holístico - do todo ao eu - com que o cenário aparece descrito por Ian pode reverberar o próprio movimento dos espaços maiores, onde também aparece o abarrotamento de pessoas, cada uma envolvida em seus afazeres (ou em seus próprios abdomens, como a aranha descrita por Bauman), mas no meio de tudo isto, há um eu, vários eus, que se esquivam aqui e ali, mas que ganham sua importância de quando são percebidos por alguém:

O centro de tratamento está abarrotado de gente andando em todas as direções: à esquerda uma criança corre em círculos enquanto a mãe cansada tenta acalmá-la; mais ao lado, um senhor de uns 70 anos balança para a frente e para trás, sustentado por uma bengala enquanto recusa qualquer tentativa de cortesia para que se sente; um pouco mais adiante, a porta de uma das salas de consulta está entreaberta e a médica olha para um prontuário, procurando por alguma informação enquanto uma mulher à frente dela espera, ansiosa. Do lado direito, um garoto alto com uma mecha de cabelo azul olha para o celular, balançando a perna em um movimento tão nervoso quanto o meu, e é impossível não notar que olha para o aparelho, mas não presta a mínima atenção naquilo. E no meio de todo aquele falatório, de médicas e enfermeiras andando de lá para cá, de pessoas insatisfeitas com a demora nas suas consultas e do ventilador empoeirado que faz mais barulho do que ventila, eu espero (ROCHA, 2018, p. 04). 
Ian esperava seu resultado do exame, mas nesta espera tivera tempo para apreciar o seu entorno, inclusive ao próprio Victor, "o garoto alto com uma mecha de cabelo azul” com quem depois iria se encontrar novamente. É como se essa cadência descritiva, que vai do "centro de tratamento" ao "eu" que espera, nos conduzisse por uma teia de pensamentos em constante rebuliço, mas neste espaço é preciso que se dê relevância às existências dali, é preciso que se dê relevância ao ser.

Novamente, nos reportando ao pensamento nietzschiano, observamos que a narrativa conduz à mesma demanda já explanada pelo filósofo, ou seja, à demanda do ser: Nietzsche tornou-se notável justamente por contrariar a premissa cartesiana que condicionava a existência do eu ao pensamento. "De onde retiro minha noção de 'pensar'? Por que crer na causa e no efeito? Com que direito posso falar de um 'eu' e de um 'eu' como causa e para cúmulo, causa do pensamento?" (NIETZSCHE, 1981, p.32). Com isso, muito se atribuiu ao filósofo um caráter pessimista, porém visto sob outro ângulo, compreendemos que, rompendo com a crença do sujeito cartesiano, ele não fazia outra coisa senão reivindicar a relevância do sujeito, do ser, de maneira que o eu fosse posto em primeiro lugar - é o ser que importa e que existe mesmo onde o pensamento não.

De quando Henrique ensaia sua resposta ao primeiro contato de Ian - "Oi, a gente não se conhece, mas o Victor me passou o seu número e me disse que a gente poderia conversar. Sou o Ian, tudo bem?" (ROCHA, 2018, p. 43) - é essa demanda, para se oferecer relevância ao ser, que vemos sendo atendida, bem como a demanda de se ultrapassar a rede frenética de pensamentos à nossa volta e focarmos o outro que precisa de nós. Henrique pensa se compensaria iniciar uma conversa com Ian ou deixaria aquele contato morrer ali, como se fosse o encontro com estranho, descrito por Bauman (2001), a render apenas uma história que não deve ser continuada:

considero se devo ou não respondê-lo. Penso se não seria melhor deixar a conversa morrer por ali mesmo e não me envolver com alguém que nem conheço. Por que deixei que Eric dissesse que estava tudo bem se um desconhecido fizesse contato comigo? Por que estou fazendo tantas concessões para o Victor, se ele não quer nem saber de mim? Não sirvo para ele, mas sou bom o bastante para servir de psicólogo para alguém que ele acabou de conhecer? (ROCHA, 2018, p. 43).

Antes da decisão, ocorre um processo de resgate da própria história e Henrique faz uma reflexão de como fora sua experiência desde quando descobrira estar com HIV: 
[...] sei que esse garoto deve estar aterrorizado. Já passei por tudo isso e sei como a gravidade pode parecer fora de lugar quando tantas coisas passam pela nossa cabeça. Se eu posso fazer com que ele se sinta melhor, por que deveria recusar?

Se eu tivesse tido alguém para me dizer que tudo ficaria bem, será que precisaria ter passado por tantas noites com o rosto enfiado no travesseiro, sufocando gritos e choro? Eu me lembro que, quando descobri meu diagnóstico, tudo o que queria era ter alguém com quem conversar, e a perspectiva de falar com um desconhecido tinha começado a me parecer possível (ROCHA, 2018, p. 44).

As relações entre os personagens se desenvolvem de maneira continuada, de maneira a existir a oportunidade da vista, da entrevista e da revista entre eles. Ian reparou em Victor no momento da consulta, os dois se falaram no ponto de ônibus e, posteriormente, os dois irão se encontrar. Do mesmo modo, o contato entre Ian e Henrique também irá se abrir para outros. Assim, vemos que o tempo moderno, em que se situam os três jovens, não os transformou em sujeitos consumidores, ou seja, em sujeitos para os quais as relações de afeto foram transmutadas em relação de consumo. Segundo Bauman,

na sociedade de consumidores, ninguém pode se tornar sujeito sem primeiro virar mercadoria, e ninguém pode manter segura sua subjetividade sem reanimar, ressuscitar e recarregar de maneira perpétua as capacidades esperadas e exigidas de uma mercadoria vendável (BAUMAN, 2001, p. 7).

Na sociedade moderna, os sujeitos não se dão ao luxo das identificações, assim, a leitura realizada um dos outros se constitui sempre falha, não permitindo o fluir das expectativas, sua pluralização e sua transformação em experiências. Ocorre como se eles permanecessem na primeira impressão, semelhantemente a um produto, por exemplo - se este não atende à expectativa presente (ou mesmo se atende de pronto), o intento imediato é comprar outro produto que esteja como novidade do momento - assim, ocorrem vários experimentos (vários produtos (vários sujeitos) são experimentados), mas nenhum deles dura tempo suficiente para poder ancorar-se como uma real experiência de vida.

Num momento mais avançado da história, depois que Victor já tinha se reaproximado e se afastado novamente de Henrique, ressoa em sua mente um discurso bem projetado no mundo moderno: "bola para a frente. Respire fundo, Victor. Outros caras aparecerão na sua vida, outras oportunidades serão construídas ao longo do tempo" (ROCHA, 2018, 135). Por um lado, podemos dizer que esta seria uma maneira otimista de encararmos a vida, por outro 
avaliamos o quanto ela projeta a possibilidade de facilmente substituirmos as pessoas, "bola para frente", pois outras virão. De fato, "outras oportunidades serão construídas ao longo do tempo", mas o conceito de mundo moderno, escopo de nossa análise, perpetua um excesso dessa maneira de pensar, em que se perderam os fios de enraizamento das relações afetivas e parece não haver mais a necessidade de as pessoas permanecerem na vida das outras, elas apenas devem passar.

Nesse viés, Coracini (2005) pontua que

constituindo momentos de prazer que, seguidos uns dos outros, parecem garantir a felicidade, ainda que passageira, a mercadoria colabora para a construção do que se poderia chamar mundo descartável e, na avalanche dos objetos, vão de embrulho os seres humanos que se transformam também em objetos descartáveis, com os quais não se constroem laços sociais, não há envolvimento, pelos quais não se têm responsabilidade... (CORACINI, 2005, p. 18).

No trecho abaixo, temos um processo de autorreflexão de Victor no que tange ao preconceito com que avaliara, inicialmente, a situação de Henrique. Avaliamos que o preconceito termina quando Victor conseguiu romper com as expectativas iniciais sobre os rapazes e sobre si, assim, ele pode se colocar como alguém que era outro antes de conhecêlos, ou seja, antes de criar laços afetivos e perceber que o HIV, de forma alguma, poderia ser um elemento com que se equacionasse a índole de alguém:

Sinto raiva de mim mesmo porque começo a pensar em quem eu era antes de conhecê-los; em como achava que as pessoas que pegavam qualquer tipo de DST mereciam as doenças por terem sido estúpidas o bastante por não terem se cuidado. Porque foram promíscuas. Porque se deixaram levar por uma situação facilmente contornável.

Mas a questão é que nem Henrique nem Ian tiveram segundas chances, e é hipocrisia pensar que sou melhor do que eles quando nem sei que tipo de vida sexual cada um deles leva ou levou. Por tudo o que sei, posso ter transado com muito mais gente do que Ian ou Henrique; quem sou eu para julgar o que aconteceu com eles? (ROCHA, 2001, p. 98).

O fato de Victor perceber o quanto mudara sua visão e o quanto estava errado antes só nos faz reavivar a equação existente entre conhecer e ler o outro. Criar laços afetivos se constitui por meio de um processo de leitura. Portamo-nos como um texto e a vida se faz um texto contínuo. Para Coracini: 
O que significar ler? Sem buscar respostas formalizadas nas teorias sobre leitura, ler pode ser definido pelo olhar, perspectiva de quem olha, de quem lança um olhar sobre um objeto, sobre um texto, seja ele verbal ou não. Esse olhar pode ser direto, atravessado ou enviesado, conforme o leitor, o espectador, o observador, sua bagagem de vida, o contexto social no qual se insere: momento e espaço (lugar), suas expectativas, que alguns denominam projeto, intenção ou objetivo. Nem sempre ou quase nunca tais expectativas são conscientes. Mas até mesmo essa percepção - de maior ou menor consciência - depende da concepção de leitura que adotamos (CORACINI, 2005, p. 19).

À leitura, aqui, pode ser conferido certo caráter de alteridade, e ler passa a ser o gesto de olhar o outro. No caso de Victor, sua primeira leitura de Ian e Henrique se deu por meio de um olhar enviesado, mas depois o olhar foi recompondo-se conforme fluíam as expectativas de Victor. Sua leitura também proporcionou entendermos que um bom ou um mau texto não depende apenas das expectativas que nele acumulamos - devemos mudar a nós mesmos, reconhecer nossos erros, voltar ao texto e lê-lo de novo. Devemos, pois, dar caminho à continuidade dos textos e recompor nossas leituras falhas; há sempre tempo para isso a exemplo do que Ian coloca no primeiro capítulo da história, abrindo o texto: "o primeiro passo é admitir para você mesmo que, não importa qual seja o resultado, a vida continua" (ROCHA, 2018, p. 04).

\section{Considerações finais}

$\mathrm{O}$ afeto constitui o foco da narrativa de Você tem a vida inteira. $\mathrm{O}$ amor e a amizade são apresentados sob três perspectivas que projetam uma relação sorodiscordante. O vírus HIV não corrompe as relações, não tornam as personagens estranhas. A narrativa nos leva a compreender que a amizade se torna um dispositivo poderoso no combate ao preconceito, à diferença e à solidão que marcam as vidas de Ian, Victor e Henrique.

O capítulo sete ilustra bem a força da amizade. Nessa parte da narrativa, Henrique tem apoio de seus amigos e consegue vencer o ódio e o despeito de Carlos (seu ex-namorado), em que eles vão à casa do mesmo e mandam a mensagem que: "O HIV não mata. Preconceito sim" (ROCHA, 2018, p. 276).

Em A coisa mais próxima da vida, James Wood compartilha que "a literatura, como arte, luta contra a arrogância do tempo - faz de nós insones nos salões do hábito, oferece resgatar da morte a 
vida das coisas" (WOOD, 2017, p. 60). De fato, a obra em exame cumpre em afirmar as palavras do autor, apontando para um final positivo e que não descarta as incertezas de uma vida inteira.

Em outras palavras, o romance de Lucas Rocha evidencia principalmente para nossa juventude uma obra que trata das relações afetivas diante do vírus HIV e nessa demanda consegue estabelecer uma reflexão importante sobre a vida, resgatando-a da morte.

\section{REFERÊNCIAS}

CORACINI, M. J. R. F. Concepções de Leitura na (Pós-)Modernidade. In: LIMA, R. C. de C. P. (Org.). Leitura: múltiplos olhares. Campinas: Mercado de Letras; São João da Boa Vista: Unifeob, 2005, p. 15-44.

BAUMAN, Zygmunt. Modernidade Líquida. Tradução de Plínio Dentzien. Rio de Janeiro: Jorge Zahar, 2001.

NIETZSCHE, Friedrich. Além do bem e do mal. Tradução de Marcio Pugliesi. Hemus: São Paulo, 1981.

ROCHA, Lucas. Você tem a vida inteira. Rio de Janeiro: Galera Record, 2018.

WOOD, James. A coisa mais próxima da vida. Tradução de Célia Euvaldo. SESI: São Paulo, 2017. 